ORIGINAL ARTICLE

\author{
Stuart A. Batterman · Alfred Franzblau \\ James B. D'Arcy · Nicholas E. Sargent \\ Kenneth B. Gross · Richard M. Schreck

\section{Breath, urine, and blood measurements as biological exposure indices of short-term inhalation exposure to methanol}

Received: 1 August 1996 / Accepted: 24 January 1998

\begin{abstract}
Due to their transient nature, short-term exposures can be difficult to detect and quantify using conventional monitoring techniques. Biological monitoring may be capable of registering such exposures and may also be used to estimate important toxicological parameters. This paper investigates relationships between methanol concentrations in the blood, urine, and breath of volunteers exposed to methanol vapor at $800 \mathrm{ppm}$ for periods of $0.5,1,2$, and $8 \mathrm{~h}$. The results indicate factors that must be considered for interpretation of the results of biological monitoring. For methanol, concentrations are not proportional to the exposure duration due to metabolic and other elimination processes that occur concurrently with the exposure. Firstorder clearance models can be used with blood, breath, or urine concentrations to estimate exposures if the time that has elapsed since the exposure and the model parameters are known. The 0.5 to 2 -h periods of exposure were used to estimate the half-life of methanol. Blood data gave a half-life of $1.44 \pm 0.33 \mathrm{~h}$. Comparable but slightly more variable results were obtained using urine data corrected for voiding time $(1.55 \pm 0.67 \mathrm{~h})$ and breath data corrected for mucous membrane desorption $(1.40 \pm 0.38 \mathrm{~h})$. Methanol concentrations in blood lagged some 15-30 min behind the termination of exposure, and concentrations in urine were further delayed.
\end{abstract}

S.A. Batterman $(\bowtie) \cdot$ A. Franzblau Environmental and Industrial Health

The University of Michigan

109 Observatory Drive

Ann Arbor, MI 48109-2029, USA

e-mail: STUARTB@UMICH.EDU

Tel: + 1-734-763-2417

Fax: + 1-734-764-9424

J.B. D'Arcy - N.E. Sargent - K.B. Gross · R.M. Schreck The General Motors Corporation

Research \& Development Center

Department of Automotive Safety and Health Research

30500 Mound Road

Warren, MI 48090-9055, USA
Although breath sampling may be convenient, breath concentrations reflect end-expired or alveolar air only if subjects are in a methanol-free environment for $30 \mathrm{~min}$ or more after the exposure. At earlier times, breath concentrations included contributions from airway desorption or diffusion processes. As based on multicompartmental models, the desorption processes have half-lives ranging between 0.6 and $5 \mathrm{~min}$. Preliminary estimates of the mucous membrane reservoir indicate contributions of under $10 \%$ for a 0.5 -h exposure and smaller effects for longer periods of exposure.

Key words Biological monitoring - Breath sampling · Exposure assessment - Industrial hygiene

Methanol $\cdot$ Solvents

\section{Introduction}

Exposure to many compounds can be detected and potentially quantified using biological monitoring, i.e., the measurement of a target compound or a metabolite in breath, blood, urine, tissue, sweat, or saliva. Such monitoring may be used to estimate doses resulting from all exposure pathways, i.e., percutaneous absorption, inhalation, and ingestion (Murthy and Halperin 1995), and to advance knowledge related to the absorption, distribution, and elimination of chemicals in the body (Droz and Fiserova-Bergerova 1992). Many health standards include criteria for both short- and long-term exposure to airborne contaminants so as to reflect the health significance of the accumulated dose and the dose rate, and biological monitoring may be used to evaluate exposure to many contaminants. For example, the threshold limit values include both 15-min (TLV-STEL) and 8-h (TLV-TWA) air concentrations, which for methanol are 250 and $200 \mathrm{ppm}\left(310\right.$ and $\left.260 \mathrm{mg} / \mathrm{m}^{3}\right)$, respectively, and the biological exposure index (BEI) corresponding to the TLV-TWA is a methanol concentration of $15 \mathrm{mg} / 1$ urine (ACGIH 1991). 
Transient exposures, which may cause high dose rates, can be both difficult and costly to monitor (Rappaport and Spear 1988). Many exposures in the workplace and elsewhere can be considered transient, a result of changes in factors such as chemical emissions, ventilation, and worker movement. Moreover, shortterm high-concentration exposures may involve physiological mechanisms somewhat or very different from those of long-term exposures, with the possibility that the biologically effective dose is not proportional to the exposure time or concentration, in contrast to conventional assumptions. For example, high levels of exposure may saturate certain metabolic pathways (Kavet and Nauss 1990; Droz and Fiserova-Bergerova 1992), and the absorption of solvents in the mucous membrane of the respiratory tract may affect the kinetics and uptake of water-soluble vapors (Franzblau et al. 1995; Kumagai and Matsunaga 1995). Biological monitoring may be used to estimate the effective dose, partially or fully defusing the biological issues related to uptake, redistribution, and metabolism as well as the practical difficulties of measuring concentrations with high time resolution.

This paper presents results from an experimental study of methanol exposure that examines responses seen in blood, breath, and urine samples collected from subjects exposed to methanol vapor at $800 \mathrm{ppm}$ for periods ranging from $30 \mathrm{~min}$ to $8 \mathrm{~h}$. The study investigates clearance, the relationship between exposure duration, dose, and uptake rate, and the effectiveness of breath, blood, and urine measurements as BEIs. This is the first study to examine the relationship of blood, urine, and breath samples to controlled inhalation exposures to methanol of varying duration. A concentration above the TLV is used that may be relevant to both occupational and nonoccupational settings where intermittent and uncontrolled exposure can occur.

Methanol is a widely used solvent and potential motor vehicle fuel, and workplace exposures have resulted in cases of acute toxicity (Kavet and Nauss 1990). A number of experimental and field studies have addressed the relationship between inhalation exposures to methanol and biological indicators, including methanol and formate in end-shift urine and methanol in blood (e.g., Leaf and Zatman 1952; Sedivec et al. 1981; Kawai et al. 1991, 1992; Franzblau et al. 1992b, 1997; Yasugi et al. 1992) as well as breath monitoring (Lee et al. 1992; Franzblau et al. 1992a, 1995). Methanol readily passes into and through the skin, and the role of the dermal exposure pathway has been demonstrated in several reports (Dutkiewicz et al. 1980; Franzblau et al. 1995; Batterman et al. 1996a; Batterman and Franzblau 1997). The pharmocokinetic models needed to interpret biological monitoring of methanol are largely generic, but models specific to methanol have been formulated (Horton et al. 1992; Perkins et al. 1995). The data described herein have not previously been presented, although many experimental details are shared in related studies by the authors (e.g., Franzblau et al. 1995, 1997;
Batterman et al. 1996a,b; Batterman and Franzblau 1997).

\section{Materials and methods}

Inhalation exposures

The exposure protocol consisted of separate sessions for each subject, scheduled at least 1 week apart. Each of the four core subjects stayed in the exposure chamber for 30,60, and $120 \mathrm{~min}$, and each repeated the session a second time (and a third time in the case of one subject in the 120-min exposure). Thus, the total shortterm sample consisted of 3 exposure durations $\times 4$ subjects $\times$ replicates +1 additional replicate $=25$ sessions. In addition, 15 sessions of 8 -h duration and 12 sessions as controls were conducted. The 8-h exposures included different (noncore) subjects, some of whom also participated in the control exposures. Similar procedures were followed in each session, including controls, although the timing of collection of some samples varied slightly as described below.

Exposures were conducted in a $47-\mathrm{m}^{3}$ stainless-steel exposure chamber containing a suspended floor and ceiling, a restroom, and an airlock entry. The chamber was maintained at $50 \%$ relative humidity and $22{ }^{\circ} \mathrm{C}$ and was ventilated at 18 chamber volumes $/ \mathrm{h}$ with air filtered for particulate and gaseous contaminants. Methanol vapor was introduced via a two-stage vapor generator and metered into the ventilation air flow using a mass flow controller to achieve the desired concentration of $800 \mathrm{ppm}$. A dedicated MIRAN 1-A (Foxboro Co., Foxboro, MA) infrared analyzer continuously monitored chamber air in each session. Concentrations were maintained within $\sim 1 \%$ of the target concentration.

Breath sampling and analysis

Two breath samples were collected at $\sim 10$ and $\sim 15$ min before each short-term exposure session. Breath samples were collected at $0,15,30$, and $45 \mathrm{~min}$, as well as $1,1.5,2,3,4,5,6,7$, and $8 \mathrm{~h}$ after departure from the exposure chamber in the 30-min duration and control sessions. A similar schedule was followed for the longerexposure sessions, but to keep the sessions' length to 8 or $9 \mathrm{~h}$, the final sample and the last two samples were eliminated for 1- and 2-h exposures, respectively. In the 8-h exposure, single breath samples were collected prior to exposure, immediately upon departure from the exposure chamber, and at 5, 10, and 15-min thereafter.

Breath samples were collected using a breath maneuver and sampling system that captured alveolar air in 0.51 aluminized Mylar gas-sampling bags (Quintron Instrument Co., Milwaukee, Wis.). The gas-sampling bags were analyzed for methanol and carbon dioxide $\left(\mathrm{CO}_{2}\right)$ using Fourier transform infrared (FTIR) analysis within 1 day of sampling. $\mathrm{CO}_{2}$ measurements were taken to ensure that breath samples represented alveolar air. After warming of the sampling bag the sample was transferred to an evacuated 5-m path-length gas cell of a Bomem MB-100a (Montreal, Canada) FTIR spectrometer equipped with a mercury-cadmium-telluride (MCT) nitrogen-cooled detector. Cell pressure was maintained at $500 \mathrm{mmHg}$ to avoid sample condensation. IR spectra were collected at $2 \mathrm{~cm}^{-1}$ resolution using 32 scans and were fitted using an ordinary least-squares procedure and reference spectra, e.g., $2 \% \mathrm{CO}_{2}$ in $\mathrm{N}_{2}$ (Scotts Specialty Gases, Troy, Mich.) and 50 and $1000 \mathrm{ppm}$ methanol in $\mathrm{N}_{2}$. The limit of detection (LOD) for methanol was $\sim 0.5 \mathrm{ppm}$, and the coefficient of variation (COV) was $\sim 2 \%$.

Blood sampling and analysis

Blood samples were collected at 0,15 , and $30 \mathrm{~min}$ as well as 1, 2, 3, $4,5,6$, and $7 \mathrm{~h}$ following exposure in the short-term and control sessions and at 6 and $8 \mathrm{~h}$ into the 8 -h duration session. The 7-h 
sample was omitted in the 2-h exposure session. Two samples were also collected prior to exposure. Blood was drawn from the subject's arm into a "gray top" Vacutainer tube (containing potassium oxalate and sodium fluoride), which was immediately refrigerated. Methanol concentrations were determined for two replicates of each blood sample using head-space gas chromatography and flame ionization detection. For these measurements the LOD was $\sim 0.5 \mathrm{mg} / 1$ and COVs were $3-5 \%$.

Urine sampling and analysis

All voided specimens were collected by subjects in standard hospital-collection containers and were immediately measured for volume and specific gravity by refractometry. Void specimens were requested prior to the exposure and at the end of the session. Otherwise, spontaneous voids were collected. Aliquots were stored at $4{ }^{\circ} \mathrm{C}$ for later analyses of methanol using head-space gas chromatography. LODs recorded for methanol in urine were below $0.5 \mathrm{mg} / \mathrm{l}$.

\section{Study population}

The core subjects consisted of four women aged 41-63 years who participated in all short-term exposure sessions. The same four women, plus eight others, participated in the control sessions. In all, 3 other women and 12 men participated in the 8 -h session. Subjects were at rest during the exposure and were permitted to eat and drink freely during the experiment with the exception of alcoholic beverages during the session and the preceding $24 \mathrm{~h}$. None of the subjects had known occupational or avocational exposure to methanol, formic acid, or formaldehyde, and none smoked. The subjects provided written informed consent using forms and protocols approved by the University of Michigan School of Public Health and the General Motors Research \& Development Center.

\section{Data analysis}

Collected data were analyzed as follows. Breath concentrations were screened by elimination of the few $(<1 \%)$ observations in which $\mathrm{CO}_{2}$ levels fell below $\sim 3 \%$, indicating nonalveolar air. Baseline or preexposure concentrations were computed for each subject by averaging of observations made prior to entry into the exposure chamber. Descriptive statistics (means, standard deviations, maxima) were computed for each session and across sessions, the latter by averaging of observations across subjects and sessions at the same exposure time. Across-session urine data were somewhat more complicated to analyze due to the irregular sampling schedule. Across-session averages were estimated as the average of void specimens grouped to the nearest hour.

A first-order clearance model was used to fit observation $C_{t}$ (mg/l for blood and urine; ppm for breath) collected at time $t(\mathrm{~h})$ following exposure (Droz and Fiserova-Bergerova 1992):

$C_{t}=C_{a} \exp (-k t)+C_{b}$,

where $C_{a}$ is an initial (intercept) concentration, $k$ is the rate constant $\left(\mathrm{h}^{-1}\right)$, and $C_{b}$ is the baseline concentration or endogenous level as determined using preexposure data. To aid interpretation, $k$ is expressed as a half-life $\tau(\mathrm{h})$ such that $\tau=0.693 / k$. Parameters $C_{a}$ and $\tau$, associated standard errors, and model-fit $R^{2}$ were estimated for methanol concentrations in blood, urine, and breath for each shortterm exposure session. To avoid bias of the half-life estimate, parameters for the urine data were estimated using midinterval voiding times (Droz and Fiserova-Bergerova 1992). Data that clearly did not fit a first-order decay were omitted, e.g., concentrations that continued to rise immediately after exposure ceased, and consecutive observations clearly rising long after exposure ceased. Data falling below detection limits were also omitted. First-order models were not estimated for the 8-h sessions because samples were collected only 15 min following the end of the exposure, an insufficient duration for estimation of model parameters.
Postexposure breath data were also fitted to a multicompartmental linear model (Droz and Fiserova-Bergerova 1992):

$C_{t}=\sum_{i=1 . . n} C_{a, i} \exp \left(-k_{i} t\right)+C_{b}$,

where $C_{a, i}$ and $k_{i}$ represent the intercept (ppm) and rate constant $\left(\mathrm{h}^{-1}\right)$, respectively, of the $i$ th first-order process or compartment. Double- and triple-compartmental models $(n=2$ and $n=3$, respectively) were considered. Model parameters were estimated using a forward-difference quasi-Newton method. Although such models have been used to represent breath concentrations and mass balances for four compartments, i.e., blood, vessel-rich tissues, vessel-poor tissues, and fat (Wallace and Pellizzari 1995), the compartments may not relate to specific physiological variables. In the present case this approach is primarily used to determine times when breath sampling will reflect concentrations in blood. If the processes in Eq. 2 are independent, then the total methanol released from the $i$ th compartment is the integral of (2) from $t=0$ to $t=\infty$ or $C_{a, i} / k_{i}$ and the fraction of the total methanol released in breath by the $j$ th compartment, $f_{j}$, is:

$f_{j}=C_{a, j} / k_{j}\left[\sum_{i=1 . . n} C_{a, i} / k_{i}\right]^{-1}$.

These fractions apportion the contribution of each compartment.

Concentrations in blood were used to estimate the accumulated dose and uptake rates. Another solution of the first-order model was used to estimate the methanol uptake rate in blood occurring during the exposure $Q_{e}(\mathrm{mg} / \mathrm{h})$ :

$C_{0}=Q_{e} /(V k)\left[1-\exp \left(-k t_{e}\right)\right]+C_{b}$,

where $C_{0}$ is the concentration in blood reached immediately after departure from the exposure chamber, $V$ is the volume of body fluids ( $\sim 21$ for the subjects in the study), $k$ is the rate constant previously determined for blood, and $t_{e}$ is the duration of the exposure (h). This approach assumes first-order clearance, a constant uptake rate during the exposure, and rapid and uniform partitioning of methanol between blood and other body fluids. Because blood concentrations continued to increase for 15 or $30 \mathrm{~min}$ after exposure had ceased, possibly from desorption of methanol from the mucous membrane into the airways or due to redistribution in body compartments, a post-exposure uptake rate term $Q_{p e 1}(\mathrm{mg} / \mathrm{h})$ was estimated by combination of Eqs. 1 and 4:

$C_{15}=C_{0} \exp (-k \Delta t)+Q_{p e 1} /(V k)[1-\exp (-0.25 k)]+C_{b}$,

where $C_{15}$ is the concentration observed at $15-\min (0.25 \mathrm{~h})$ after the exposure had terminated. The postexposure uptake rate $Q_{p e 1}$ is assumed to be constant during the short (15-min) period considered: thus, $Q_{p e 1}$ approximates the average uptake over the $15-\mathrm{min}$ period. Note that $Q_{p e 1}$ may be much smaller than $Q_{e}$, the uptake rate during the exposure, and $Q_{p e 1}$ may decline rapidly over the short period considered. A similar postexposure uptake rate, $Q_{p e 2}$, was estimated for the 15 - to 30 -min period. No uptake was found at postexposure times beyond $30 \mathrm{~min}$. The total uptake of methanol absorbed over the session, $M_{\text {total }}(\mathrm{mg})$, was estimated as:

$M_{\mathrm{total}}=Q_{e} t_{e}+0.25 Q_{p e 1}+0.25 Q_{p e 2}$,

where $t_{e}$ is the exposure duration (h). Uptake rates were estimated for the $0.5-, 1-$, and 2-h periods of exposure where frequent blood sampling was available.

\section{Results}

Table 1 summarizes results obtained in blood, urine, and breath samples at each exposure duration and lists the baseline or preexposure concentrations, maximal concentrations above baseline, and concentrations above baseline obtained at $15 \mathrm{~min}$ following exposure for blood and breath (as urine voids were spontaneous, 
Table 1 Mean values and standard deviations recorded for methanol concentrations in blood, urine, and breath and model results. Maximal and model-intercept concentrations (from a onecompartment model, Eq. 1) are above baseline concentrations
Control results are based on core subjects and 8 sessions with noncore subjects; 8-h results are based on 15 sessions with noncore subjects

\begin{tabular}{|c|c|c|c|c|c|c|}
\hline \multirow{2}{*}{\multicolumn{2}{|c|}{$\begin{array}{ll}\begin{array}{l}\text { Exposure } \\
\text { duration }\end{array} & \begin{array}{l}\text { Meth } \\
(\mathrm{mg} / 1\end{array} \\
\text { Baseline concentration: }\end{array}$}} & $\begin{array}{l}\text { Tethanol in blood } \\
\mathrm{ng} / \mathrm{l})\end{array}$ & \multicolumn{2}{|c|}{$\begin{array}{l}\text { Methanol in urine } \\
(\mathrm{mg} / \mathrm{l})\end{array}$} & \multicolumn{2}{|c|}{$\begin{array}{l}\text { Methanol in breath } \\
(\mathrm{ppm})\end{array}$} \\
\hline & & & & & & \\
\hline Control & 1.9 & \pm 0.9 & 1.6 & \pm 0.7 & 0.1 & \pm 0.2 \\
\hline $30 \mathrm{~min}$ & 2.0 & \pm 0.9 & 1.1 & \pm 0.5 & 0.3 & \pm 0.6 \\
\hline $1 \mathrm{~h}$ & 1.3 & \pm 0.6 & 1.5 & \pm 1.2 & 0.5 & \pm 0.8 \\
\hline $2 \mathrm{~h}$ & 1.8 & \pm 0.7 & 1.2 & \pm 0.6 & 0.5 & \pm 0.5 \\
\hline $8 \mathrm{~h}$ & 1.8 & \pm 0.9 & 2.0 & \pm 1.7 & 0.6 & \pm 0.9 \\
\hline Mean & 1.8 & \pm 0.7 & 1.3 & \pm 0.8 & 0.4 & \pm 0.6 \\
\hline \multicolumn{7}{|c|}{ Maximal concentration: } \\
\hline Control & 0.6 & \pm 0.5 & 0.2 & \pm 0.6 & 0.5 & \pm 1.2 \\
\hline $30 \mathrm{~min}$ & 5.3 & \pm 1.4 & 3.2 & \pm 1.2 & 187.0 & \pm 25.8 \\
\hline $1 \mathrm{~h}$ & 6.6 & \pm 1.2 & 4.0 & \pm 1.4 & 140.2 & \pm 31.3 \\
\hline $2 \mathrm{~h}$ & 14.0 & \pm 1.5 & 11.0 & \pm 3.2 & 152.1 & \pm 18.5 \\
\hline $8 \mathrm{~h}$ & 30.7 & \pm 6.9 & 74.0 & \pm 33.5 & 181.4 & \pm 31.4 \\
\hline \multicolumn{7}{|c|}{ Concentration 15 min after exposure: } \\
\hline $30 \mathrm{~min}$ & 4.7 & \pm 1.9 & - & - & 4.0 & \pm 0.8 \\
\hline $1 \mathrm{~h}$ & 6.1 & \pm 1.5 & - & - & 4.8 & \pm 1.2 \\
\hline $2 \mathrm{~h}$ & 13.4 & \pm 1.8 & - & - & 7.1 & \pm 2.4 \\
\hline $8 \mathrm{~h}$ & - & - & - & - & 7.6 & \pm 1.7 \\
\hline \multicolumn{7}{|c|}{ Model-intercept concentration: } \\
\hline $30 \mathrm{~min}$ & 6.0 & \pm 2.1 & 5.8 & \pm 2.4 & 5.1 & \pm 3.8 \\
\hline $1 \mathrm{~h}$ & 7.1 & \pm 1.6 & 6.4 & \pm 2.8 & 4.3 & \pm 1.3 \\
\hline $2 \mathrm{~h}$ & 14.6 & \pm 2.9 & 13.0 & \pm 2.8 & 6.1 & \pm 1.3 \\
\hline \multicolumn{7}{|c|}{ Half-life (h): } \\
\hline $30 \mathrm{~min}$ & 1.24 & \pm 0.25 & 1.90 & \pm 0.87 & 1.51 & \pm 1.42 \\
\hline $1 \mathrm{~h}$ & 1.41 & \pm 0.27 & 1.36 & \pm 0.78 & 1.28 & \pm 0.74 \\
\hline $2 \mathrm{~h}$ & 1.63 & \pm 0.36 & 1.39 & \pm 0.37 & 1.37 & \pm 0.31 \\
\hline Mean & 1.44 & \pm 0.33 & 1.55 & \pm 0.67 & 1.38 & \pm 0.86 \\
\hline
\end{tabular}

this result was not obtained). These concentrations are averaged across subjects and replicates. The sample size for the control (no exposure) used 12 exposure sessions, 4 of which involved the core subjects; the $0.5-$ to $2-\mathrm{h}$ exposures used the 4 core subjects with $2-3$ replicates each; and the 8-h exposures used 15 sessions (involving noncore subjects). No systematic bias was noted between core and noncore subjects. Table 1 also shows the half-life and intercept statistics from first-order models, discussed below.

\section{Blood data}

Baseline or endogenous concentrations of methanol in blood averaged $1.8 \pm 0.7 \mathrm{mg} / 1$ and showed no trend by subject or exposure duration. Subjects with elevated baseline levels often maintained a differential over the session, e.g., the single highest baseline measurement $(3.4 \mathrm{mg} / \mathrm{l})$ recorded for one subject was similar $8 \mathrm{~h}$ later, well after most methanol from the inhalation exposure would have cleared. Baseline concentrations were small in comparison with levels found for 1-h or longer periods of exposure, and also with the 15-mg/l BEI reported for methanol in urine (ACGIH 1991). (Blood:urine partition coefficients are near unity.)

Figure 1 shows trends observed in methanol concentrations in blood for $0.5-, 1-$ and 2-h exposure ses-

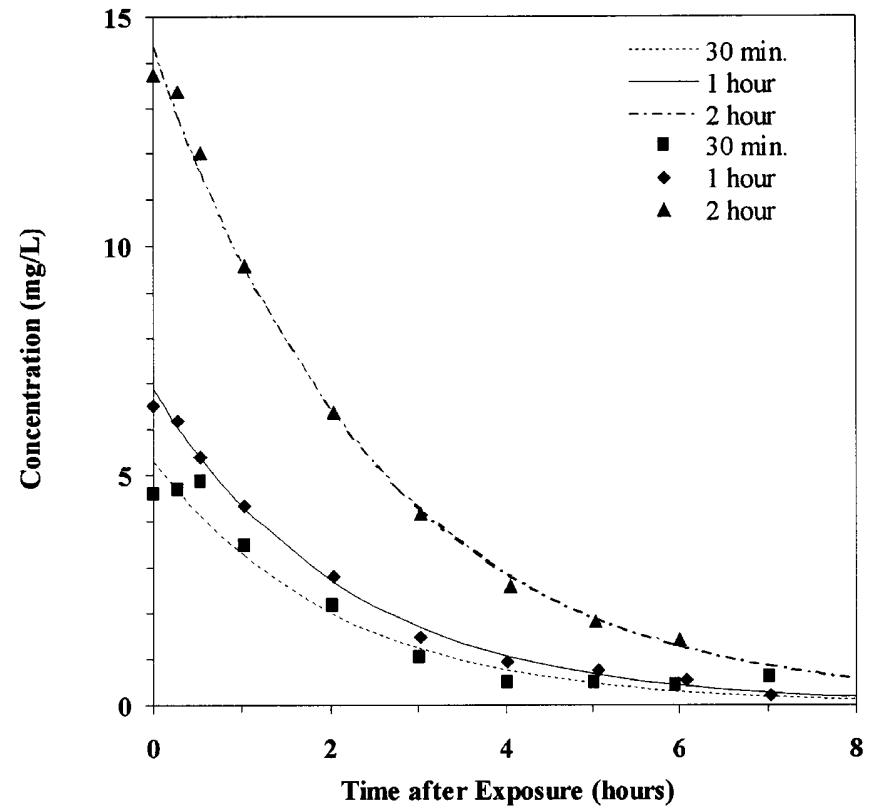

Fig. 1 Concentrations of methanol measured in blood following inhalation of $800 \mathrm{ppm}$ methanol vapor for $30 \mathrm{~min}, 1 \mathrm{~h}$, and $2 \mathrm{~h}$. Points represent values, lines show best-fit first-order models

sions. Means across the eight or nine sessions, corrected (by subtraction) for preexposure methanol levels, are plotted. Parameters of the first-order model (Eq. 1) for 
methanol in blood are listed in Table 1 and predictions are plotted in Fig. 1. Samples collected at postexposure times of 0 and $15 \mathrm{~min}$ were not used to fit these models due to the lag in the maximal concentrations, clearly seen in the 30-min duration exposure and, to a lesser extent, in the session data recorded for longer exposures. In the 30-min exposures, a delay in maxima was seen in six of eight sessions. With the exception of the samples collected at postexposure times of 0,15 , or $30 \mathrm{~min}$, the first-order models provided an excellent fit. Across all exposure durations and sessions the half-life averaged $1.44 \pm 0.33 \mathrm{~h}$ and the $R^{2}$ exceeded 0.95 . Models for individual sessions showed good fits $\left(R^{2} \geq 0.92\right.$; mean $\left.R^{2}=0.98\right)$ and no significant difference between subjects or exposure times, although results noted for individual sessions and subjects could be variable, e.g., one subject had half-lives ranging from 1.01 to $2.38 \mathrm{~h}$. This variability can occur due to subject variability, endogenous methanol production, and experimental errors, including baseline estimates. Relative measurement errors increased at the low methanol concentrations that resulted from short-duration exposures when uptake was small and at long postexposure times after substantial clearance. As discussed above, half-life estimates excluded some data, primarily initial points if maxima were not reached and tailing points if increases were detected. Although data omissions affected some session results, effects were small on averaged data. Most half-life estimates had low levels of uncertainty, and few data were excluded.

Table 1 also lists estimates obtained for the maximal methanol level using the first-order model at $t=0$, i.e., the model intercept $C_{a}$, corrected for baseline $C_{b}$. Intercepts slightly exceeded observed maxima, possibly representing a departure from the first-order model, noninstantaneous uptake, or a time lag for the redistribution of methanol.

Levels of methanol in blood predicted using the firstorder model and the estimated 1.44-hr half-life show that concentrations do not increase linearly with exposure duration but asymptotically approach the steadystate level reached after many hours of exposure. For $0.5-, 1-, 2-$, and 8-h exposure periods, maxima should reach $21 \%, 38 \%, 62 \%$, and $98 \%$ of the steady-state level, respectively. Experimental results show that doubling of the exposure duration from 1 to $2 \mathrm{~h}$ approximately doubled concentrations (from $6.6 \pm 1.2$ to $14.0 \pm 1.5 \mathrm{mg} / \mathrm{l})$, but quadrupling of the duration from 2 to $8 \mathrm{~h}$ only doubled methanol concentrations (to $30.7 \pm 6.9 \mathrm{mg} / \mathrm{l})$. These results are in general agreement with predictions.

\section{Urine data}

The analysis of the urine data parallels that for the blood data. The results are summarized in Table 1 , and observed mean values and predictions are plotted in Fig. 2. In contrast to blood data, urine data have greater vari-

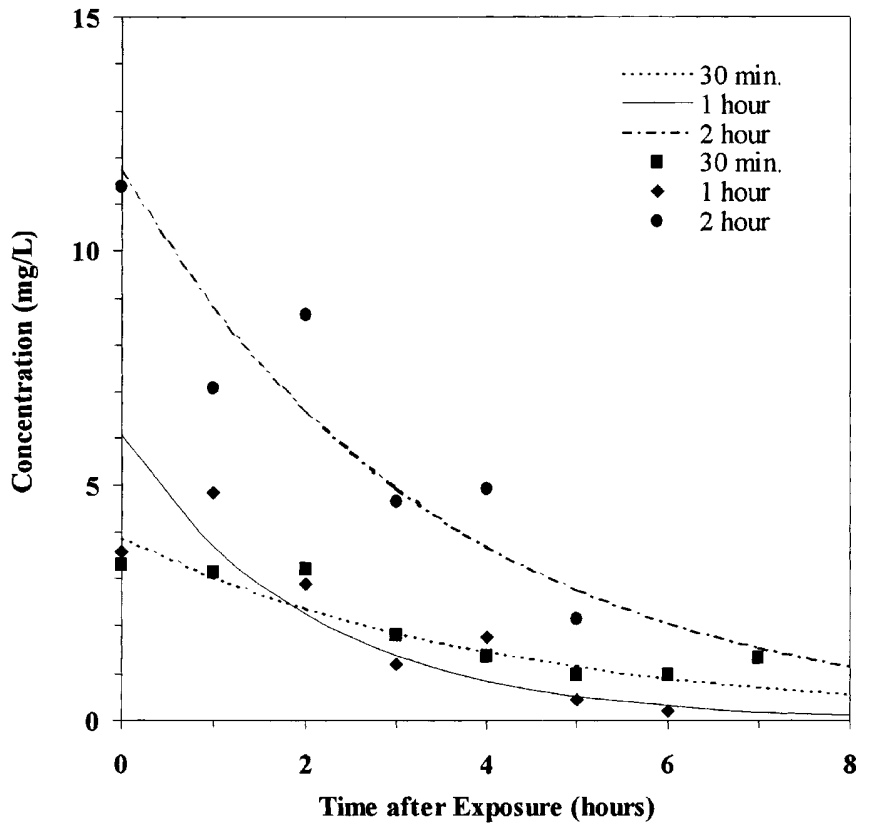

Fig. 2 Concentrations of methanol measured in urine following exposure (see legend to Fig. 1)

ability, in part due to the smaller sample size $(n=3-7$ samples, including preexposure samples) as compared with blood data (11 samples) and to the variation in voiding times following exposure. However, Figs. 1 and 2 illustrate that methanol concentrations in urine and blood agree at intermediate times following exposure.

Baseline concentrations in urine were generally small, averaging $1.3 \pm 0.8 \mathrm{mg} / \mathrm{l}$. As observed for the blood data, elevated baselines were often maintained over the 8- to 9-h duration sessions. Maximal concentrations increased with exposure time, although trends seen for individual sessions were sometimes inconsistent until the exposure duration reached $2 \mathrm{~h}$. The average concentrations across individuals and replicates increased monotonically, but some increases were small, e.g., from $3.2 \pm 1.2$ to only $4.0 \pm 1.4 \mathrm{mg} / \mathrm{l}$ for 0.5 - and 1 -h periods of exposure, respectively. As compared with the 1-hr exposure, concentrations increased 3-fold for the 2-h exposure $(11.0 \pm 3.2 \mathrm{mg} / \mathrm{l})$ and 7 -fold for the 8-h exposure $(74 \pm 33 \mathrm{mg} / \mathrm{l})$. The 8 -h exposure yielded urinary concentrations $23 \%$ higher than that expected by scaling of the ACGIH BEI from $15 \mathrm{mg} / 1$ for a 200-ppm 8-h exposure to $60 \mathrm{mg} / \mathrm{l}$ for a $800-\mathrm{ppm} 8$-h exposure.

Urinary methanol levels closely fit first-order models and most sessions had $R^{2} \geq 0.9$. Model intercepts for individual sessions showed moderate variation, a result of the few data points available and the need for a 2-h extrapolation in most cases, i.e., spontaneous voids were generally collected several hours after departure from the exposure chamber. (No such extrapolation was needed for blood since samples were collected immediately upon exit from the chamber.) Model intercepts exceeded maxima, especially for the 0.5 - and 1 -h exposures. These predictions represent concentrations in ur- 
ine at the time of the peak methanol concentration in blood. Since the corresponding void samples were generally unavailable, predictions cannot be verified. However, predicted levels $(5.8,6.4$, and $13.0 \mathrm{mg} / 1$ for $0.5,1$ and 2-h durations, respectively) closely matched maxima in blood $(5.3,6.6$, and $14.0 \mathrm{mg} / 1$, respectively). At equilibrium, methanol concentrations in blood and urine should be similar, although blood concentrations will be slightly lower due to its higher lipid content.

Half-life estimates based on urine data were comparable with those based on blood samples, though levels of uncertainty were higher, particularly for the short-

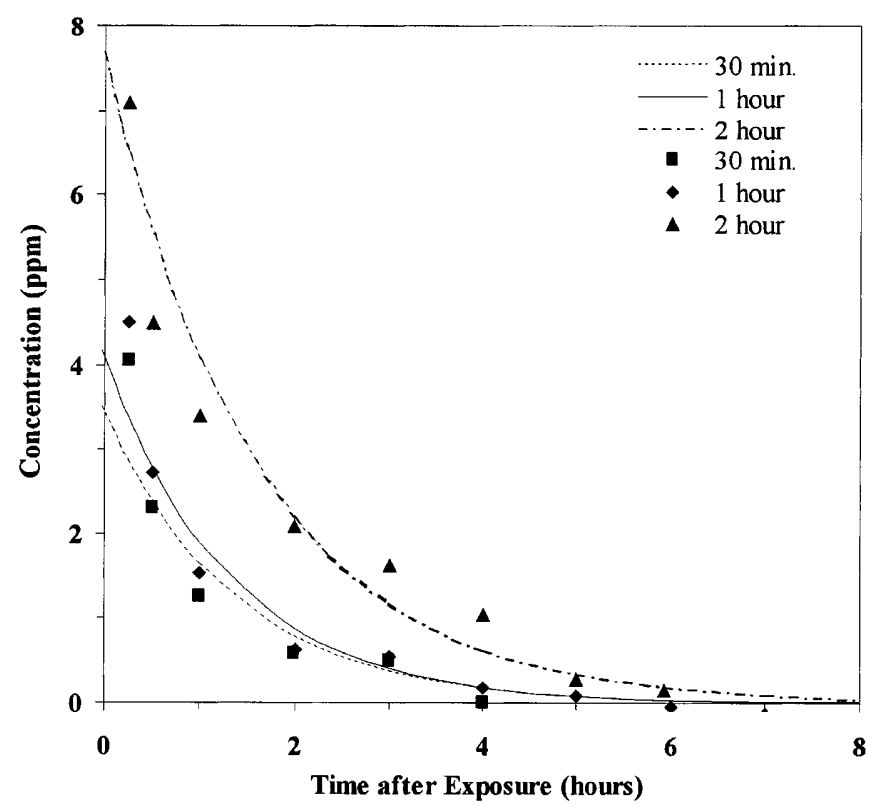

Fig. 3 Concentrations of methanol measured in breath following exposures. Only data recorded at $\geq 15 \mathrm{~min}$ after exposure are plotted and modeled (see legend to Fig. 1) duration exposures, where analytical uncertainties and errors in baseline estimates may have obscured increments due to the inhalation exposure.

\section{Breath data}

Methanol concentrations in breath are summarized in Tables 1 and 2 and plotted in Fig. 3. Data collected at 0 , 5 , and $10 \mathrm{~min}$ after exit from the chamber are not plotted, as they would be off-scale. Baseline levels of methanol in breath were low $(0.4 \pm 0.6 \mathrm{ppm})$.

The highest methanol concentrations were measured immediately after departure from the exposure chamber. Mean concentrations ranged from 140 to $187 \mathrm{ppm}$ (109 to $205 \mathrm{ppm}$ for individual sessions), and no relationship to exposure duration was observed. Concentrations declined rapidly after exit from the chamber (Table 2). As discussed by Franzblau et al. (1995), Kumagai and Matsunaga (1995), and other investigators, concentrations of water-soluble compounds such as methanol in breath samples can reflect concentrations in the liquid film surrounding the mucous membranes rather than alveolar air. Because these breath concentrations did not vary with exposure time, the mucous membrane, or at least its outer film in contact with the chamber air, was apparently "saturated" with methanol at all tested exposure durations. Concentrations in breath recorded immediately after exposure (averaging $160 \pm 30 \mathrm{ppm}$ ) were well below the chamber concentration $(800 \mathrm{ppm})$. At 15 min after exposure, concentrations in breath were much lower as the mucous membranes had apparently desorbed the "excess" methanol. Breath concentrations noted at a postexposure time of 15 min showed monotonic increases with exposure duration, though the increase observed from 30-min to 1-h exposures was small (from $4.0 \pm 0.8$ to $4.8 \pm 1.2 \mathrm{ppm}$ ), as was the increase

Table 2 Statistics of methanol concentrations in blood and breath and the breath predictions based upon equilibrium partitioning with blood and the indicated partition coefficients (NA No blood measurement taken)

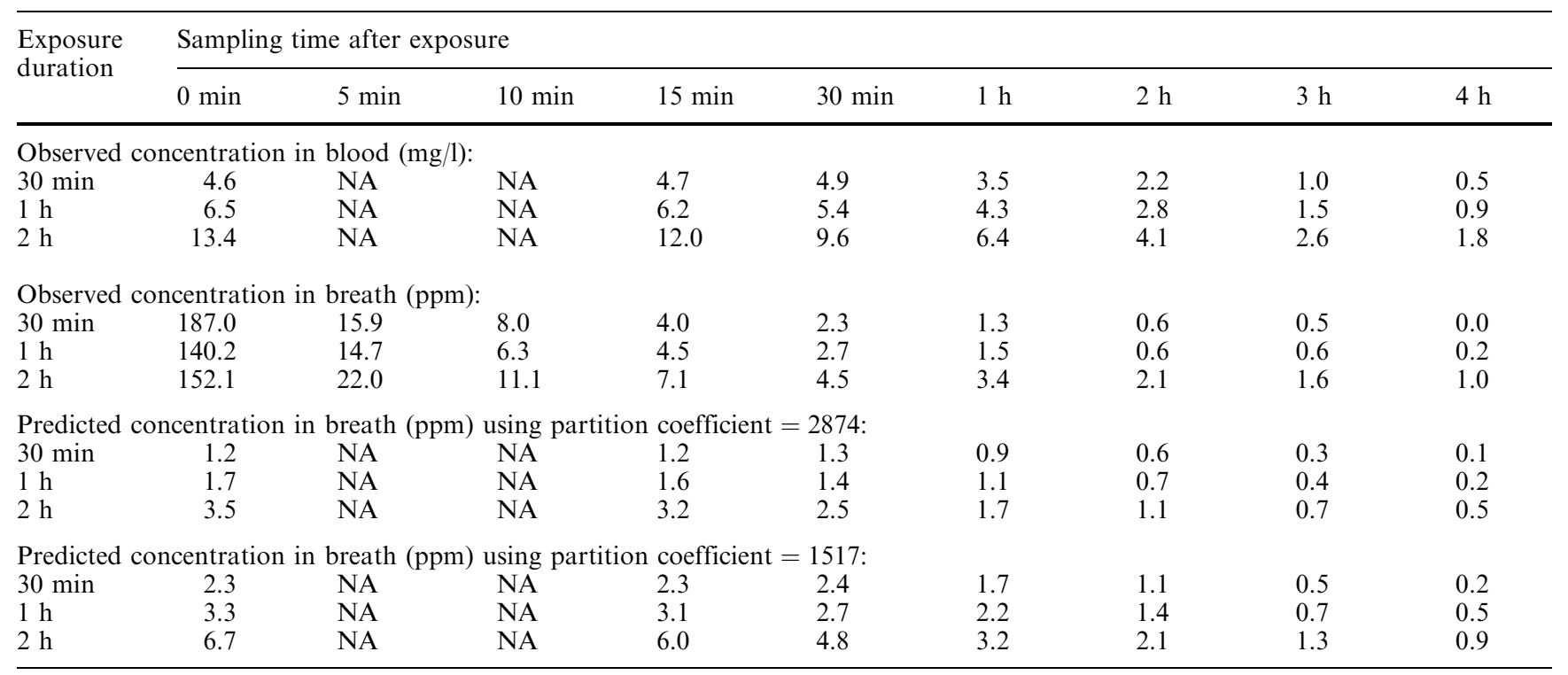


seen from 2- to 8-h exposures from $(7.1 \pm 2.4$ to $7.6 \pm 1.7 \mathrm{ppm})$. In contrast, methanol in blood doubled in the 1- to 2-h exposures and also in the 2- to 8-h exposures. The similar concentrations observed in breath suggest that desorption from the mucous membranes was incomplete at a postexposure time of $15 \mathrm{~min}$. The multicompartmental models, discussed below, confirm these trends.

First-order models were estimated using breath samples collected at $15 \mathrm{~min}$ to $6 \mathrm{~h}$ after departure from the exposure chamber (Fig. 3). Model fits were high $\left(0.89 \leq R^{2} \leq 0.96\right)$. The mean estimated half-life $(1.38 \pm 0.86 \mathrm{~h})$ was slightly shorter than that found using blood or urine data. On omission of the data from e.g., 0-30 min, $0-1 \mathrm{~h}$, and $0-2 \mathrm{~h}$, half-life estimates considerably lengthened, apparently a result of exclusion of the desorption processes. Again, the multicompartmental models provide a way to address these changes (artifacts) in the half-life estimated from breath data.

\section{Comparison of blood and breath data}

Table 2 lists the average concentrations of methanol observed in blood and breath and those predicted in breath using two blood:air partition coefficients: 2874 (Pezzagno et al. 1983) and 1518 (Fiserova-Bergerova and Diaz 1986). For postexposure times of less than $\sim 1 \mathrm{~h}$, observed concentrations in breath exceeded pre- dictions, indicating that concentrations detected in breath were not in equilibrium with those found in blood. Differences were small at post-exposure times of $0.5-1 \mathrm{~h}$. In contrast to previous work, where the larger partition coefficient was found to provide a good fit to breath samples in subjects with dermal exposure (Franzblau et al. 1995), the smaller coefficient appears more accurate. The next section confirms that $\sim 0.5 \mathrm{~h}$ is needed for full desorption of methanol from the upper respiratory tract.

Multicompartmental models for breath data

Parameters of three-compartment models calibrated for the breath data are shown in Table 3. Two-compartment models poorly fit the 5- and 10-min postexposure observations. Three-compartment models provided an excellent fit ( $R^{2} \geq 0.99$ and low relative errors). The first compartment has a short half-life (0.25-1.2 min), a high initial concentration (103-151 ppm), and accounts for $4-39 \%$ of the exhaled methanol. The second compartment has an intermediate half-life (3.7-7.5 $\mathrm{min})$ and a moderate initial concentration $(8.2-44 \mathrm{ppm})$. These compartments may reflect fast and slow desorption processes from the mucous membranes. The third compartment had the slowest release rate (half-life 0.99 $1.74 \mathrm{~h})$ and a low initial concentration $(2-5.1 \mathrm{ppm})$, slightly below the concentrations measured at $15 \mathrm{~min}$

Table 3 Parameters of the three multicompartmental models (Eq. 2 ), fitted to postexposure breath data for exposure durations of 0.5 , 1 , and $2 \mathrm{~h}$. Mean values $\pm \mathrm{SD}$ are listed for three exposure dura-

tions (Fraction Percentage of the estimated total absorbed dose by indicated compartment)

\begin{tabular}{|c|c|c|c|c|c|c|}
\hline & & \multicolumn{5}{|c|}{ Exposure duration } \\
\hline Compartment 2 & $\begin{array}{l}\text { Half-life }(\mathrm{min}) \\
\text { Intercept }(\mathrm{ppm}) \\
\text { Fraction }(\%)\end{array}$ & $\begin{array}{l}3.83 \\
34.0 \\
33.7\end{array}$ & $\begin{array}{c}7.46 \\
8.2 \\
15.6\end{array}$ & $\begin{array}{l}3.69 \\
43.6 \\
22.5\end{array}$ & $\begin{array}{l}5.00 \\
28.6 \\
24.0\end{array}$ & $\begin{array}{l} \pm 2.14 \\
\pm 18.3 \\
\pm 9.1\end{array}$ \\
\hline Compartment 3 & $\begin{array}{l}\text { Half-life }(\mathrm{hr}) \\
\text { Intercept }(\mathrm{ppm}) \\
\text { Fraction }(\%)\end{array}$ & $\begin{array}{l}1.48 \\
2.0 \\
46.0\end{array}$ & $\begin{array}{c}0.99 \\
3.0 \\
45.9\end{array}$ & $\begin{array}{l}1.74 \\
5.1 \\
73.9\end{array}$ & $\begin{array}{c}1.40 \\
3.4 \\
55.3\end{array}$ & $\begin{array}{l} \pm 0.38 \\
\pm 1.5 \\
\pm 16.1\end{array}$ \\
\hline
\end{tabular}

Table 4 Estimated contribution of desorption processes to breath concentration at the indicated postexposure times and exposure durations as based on multicompartmental models and assuming $800 \mathrm{ppm}$ exposure; 8-h results use the 2 -h model except for the intercept of the third compartment, which is scaled from blood data to $11.2 \mathrm{mg} / \mathrm{l}$

\begin{tabular}{lllll}
\hline Postexposure & \multicolumn{4}{l}{ Desorption contribution $(\%)$ for exposure duration } \\
\cline { 2 - 5 } time $(\min )$ & $30 \mathrm{~min}$ & $1 \mathrm{~h}$ & $2 \mathrm{~h}$ & $8 \mathrm{~h}$ \\
\hline 0 & 98.9 & 97.8 & 96.7 & 92.9 \\
5 & 87.8 & 80.6 & 77.7 & 61.2 \\
10 & 75.0 & 57.1 & 58.5 & 38.9 \\
15 & 55.8 & 44.7 & 36.3 & 9.4 \\
20 & 34.7 & 34.8 & 18.7 & 4.0 \\
25 & 18.3 & 26.3 & 8.5 & 1.7 \\
30 & 8.6 & 19.2 & 3.6 & 0.7 \\
35 & 3.8 & 13.6 & 1.5 & \\
\hline
\end{tabular}


after exposure or estimated as the model intercept (Table 4). The half-life for this compartment averaged $1.40 \pm 0.38 \mathrm{~h}$, similar to that estimated using blood or urine. The third compartment reflects end-expired or alveolar air, which should be in equilibrium with blood. Although the short-term compartments contributed a minor fraction of the total methanol exhaled, particularly at longer exposure durations, concentrations due to the short-term compartments were much higher, albeit briefly, than levels in alveolar air.

Table 4 shows the combined contribution of the two short-term compartments to the total breath concentration (resulting from all three compartments). For example, short-term processes account for $56 \%$ of the methanol in a breath sample taken at 15 min after a 30min, 800-ppm exposure, meaning that breath sampling will overestimate concentrations in blood by a factor of 2. As blood concentrations increase with longer exposure times, these contributions will decrease. For 1- and 2-h exposures, short-term processes contribute $45 \%$ and $36 \%$, respectively, of methanol concentrations at 15 min. Effects on 8-h exposures are estimated in Table 4 using parameters of the 2-h model, except that the intercept of the third compartment is set to $11.2 \mathrm{mg} / \mathrm{l}$, scaled from the 2-h data using 2- and 8-h concentrations in blood. For an 8-h exposure, short-term processes account for $21 \%$ of methanol at $15 \mathrm{~min}$. Additional time reduces the contributions of the short-term processes. Assuming that $5 \%$ contributions are acceptable, $\sim 30 \mathrm{~min}$ in a methanol-free environment is required, and somewhat less time is needed for longer periods of exposure.

Methanol uptake rates and doses

Table 5 lists the uptake rates and doses estimated using the blood data and Eqs. 4-6. The uptake rate $Q_{e}$ found for the short-term exposures, 346 to $448 \mathrm{mg} / \mathrm{h}$, was substantially below the $587-\mathrm{mg} / \mathrm{h}$ rate noted for the $8-\mathrm{h}$ exposures. Uptake into blood continued for $15 \mathrm{~min}$ after the termination of exposure, with the average rate being $131 \pm 76 \mathrm{mg} / \mathrm{h}$. Some uptake appeared to continue in the 15- to 30-min postexposure period, but results were inconsistent. The contribution of postexposure uptake is indicated in the lower portion of Table 5. Post-exposure uptake accounts for $10 \%$ of the total uptake in the 30 min exposures and for 5-6\% in the 1- and 2-h exposures.

The higher uptake rates recorded for the 8-h exposures may be attributable to differences in the study population. The 8 -h exposures used a group that was younger $(38 \pm 14$ versus $54 \pm 4$ years), taller $(177 \pm 8$ versus $166 \pm 1 \mathrm{~cm})$, slightly heavier $(79 \pm 18$ versus $78 \pm 13 \mathrm{~kg}$ ), more numerous (15 versus 4 subjects), and predominantly male ( $80 \%$ men versus $100 \%$ women). In addition, the clearance of methanol may have been slower in the 8-h exposure group due to (partial) metabolic saturation. If so, the use of the 1.44-h half-life, which would be incorrect at that exposure level, would increase the apparent uptake rate. Thus, although subjects in the 0.5 - to 2 -h exposures were identical and their results are comparable, they should not be compared with the uptake rates noted for the 8-h exposure group.

\section{Discussion}

Interpretation of breath samples

Although it is the easiest of the three BEIs to sample and analyze, the interpretation of breath samples is complicated by the uptake and release of methanol in the moist surfaces and, possibly, deeper layers within the head airways and tracheobronchial regions. Many anatomical, physiological, and chemical factors can influence the uptake and retention of water-soluble vapors, including mouth versus nose breathing, solubility and diffusion rates of the vapor, airway dimensions, and respiratory characteristics, e.g., flow rate. Most surfaces in the head airways and tracheobronchial regions are covered by a thin mucous layer. The respiratory bronchioles, far down in the respiratory tract just above the alveolar

Table 5 Methanol uptake rates and total methanol uptake estimated using blood data and first-order models $\left(Q_{e}\right.$ denotes uptake during the exposure period, $Q_{p e 1}$ and $Q_{p e 2}$ apparent uptake into

blood during the postexposure periods indicated, $N A$ no blood measurement taken)

\begin{tabular}{|c|c|c|c|c|c|c|c|}
\hline \multirow{2}{*}{$\begin{array}{l}\text { Exposure } \\
\text { duration }\end{array}$} & \multirow{2}{*}{\multicolumn{2}{|c|}{$\begin{array}{l}\text { During exposure } \\
Q_{e}\end{array}$}} & \multicolumn{4}{|c|}{ Postexposure } & \multirow[t]{2}{*}{ Total } \\
\hline & & & \multicolumn{2}{|c|}{$Q_{p e 1}(0-15 \mathrm{~min})$} & \multicolumn{2}{|c|}{$Q_{p e 2}(15-30 \mathrm{~min})$} & \\
\hline \multicolumn{8}{|c|}{ Uptake rates $(\mathrm{mg} / \mathrm{h})$ : } \\
\hline $30 \mathrm{~min}$ & 432 & & 109 & & 161 & & NA \\
\hline $1 \mathrm{~h}$ & 346 & & 69 & & -14 & & NA \\
\hline $2 \mathrm{~h}$ & 448 & & 215 & & 31 & & NA \\
\hline $8 \mathrm{~h}$ & 630 & & NA & & NA & & NA \\
\hline Average & 464 & \pm 119 & 131 & \pm 76 & 59 & \pm 91 & NA \\
\hline \multicolumn{8}{|c|}{ Uptake (mg): } \\
\hline $30 \mathrm{~min}$ & 216 & $(76 \%)$ & 27 & $(10 \%)$ & 40 & $(14 \%)$ & 284 \\
\hline $1 \mathrm{~h}$ & 346 & $(96 \%)$ & 17 & $(5 \%)$ & -4 & $(-1 \%)$ & 359 \\
\hline $2 \mathrm{~h}$ & 897 & $(94 \%)$ & 54 & $(6 \%)$ & 8 & $(1 \%)$ & 958 \\
\hline $8 \mathrm{~h}$ & 5036 & $(99 \%)$ & 33 & $(1 \%)$ & 15 & $(0)$ & 5084 \\
\hline
\end{tabular}


ducts and tracts, contribute by far the greatest surface area of mucus lined surfaces, $7.5 \mathrm{~m}^{2}$ as compared with $0.047 \mathrm{~m}^{2}$ in the head airways region (including the larynx and esophagus), $0.03 \mathrm{~m}^{2}$ in the trachea and bronchi, and $0.26 \mathrm{~m}^{2}$ in the bronchioles (ICRP 1994). Walls of the respiratory bronchioles consist of a 5- to $10-\mu \mathrm{m}-$ thick mucous membrane (Johanson 1991), a single-layer respiratory epithelium of cuboidal cells, and smoothmuscle layers. The much larger $140-\mathrm{m}^{2}$ area of the alveolar ducts and sacs consists of squamous alveolar cells without a mucous layer.

The multicompartmental model, an empirical approach to deal with a complex physiological process, suggests fast and slow release processes for the head airways and tracheobronchial regions. The mucous membranes are not homogeneous, however, and "desorption" may also reflect diffusion through a liquid film covering the mucous membrane or through cells, a process that is not expected to be of the first order. The fastest compartment (half-life $0.64 \pm 0.47 \mathrm{~min}$ ) may reflect the outermost layers of the mucous membrane that achieves near-instantaneous equilibrium with air. The second compartment (half-life $5.0 \pm 2.1 \mathrm{~min}$ ) may reflect deeper layers of the respiratory system influenced by nonequilibrium processes such as diffusion. To provide more insight into these compartments we conducted several simulations using a time-varying diffusion model. Many aspects of the data could be reproduced by modeling of uptake in a homogeneous sheet representing the moist surfaces and deeper layers within the head airways and tracheobronchial regions. Methanol uptake and release from one side of the sheet in equilibrium with methanol vapor was modeled. The sheet's opposite side was impermeable. The observed kinetics could be approximated using a sheet thickness of $0.12 \mathrm{~cm}$ (a fitted parameter), a diffusion coefficient of $10^{-5} \mathrm{~cm}^{2} / \mathrm{s}$ (an approximate value for methanol in mucus or water), and an arbitrary concentration-area product scaled to match the data (a second fitted parameter). The sheet thickness and diffusion coefficient determines the dynamics. Although the concentration-area product could not be justified, the thickness implies penetration of methanol well beyond the $\sim 10-\mu \mathrm{m}$ film that coats the airways. While simplistic, the model suggests that the physical dimension of the process is larger than the very thin mucous membrane film. However, lags in desorption processes also could result from poorly ventilated "dead" spaces or for other reasons.

Estimates of postexposure uptake (Table 5) from the desorption of solvent from the mucous membranes or some other reservoir are preliminary. The time resolution of blood sampling $(15 \mathrm{~min})$ imperfectly captures the fast desorption kinetics (half-lives 0.6 and $5 \mathrm{~min}$ ), and the small sample size and experimental errors contribute additional uncertainties. Nonetheless, a delay in maxima was seen in most of the 30-min exposure sessions. Additional evidence that mucous membranes represent a reservoir is shown by breath concentrations of 100 $200 \mathrm{ppm}$ measured upon exit from the exposure cham- ber and by concentrations that remained elevated for 15-30 min. For the shortest exposures tested this reservoir probably contributed no more than $10 \%$ of the total uptake. For exposures exceeding $\sim 1-2 \mathrm{~h}$, its effect appears negligible. This reservoir may be important for brief exposure to water-soluble vapors, where it increases uptake.

Several physiologically based models take into account the absorption of solvents in the mucous membrane of the respiratory tract, including nasal uptake of solvents (Gerde and Dahl et al. 1991; Morris et al. 1993), uptake of solvents in the wall of the respiratory tract (Johanson 1991), and the kinetics of the mucous layer (Kumagai and Matsunaga 1995). Kumagia and Matsunaga (1995) considered only the outermost layer $(\sim 1-$ $5 \mu \mathrm{m}$ thick) of the mucous membrane and a $\sim 0.5-\mathrm{m}^{2}$ region above the terminal bronchioles, giving a mucous volume of $0.5-2.5 \mathrm{~cm}^{3}$. This layer was assumed to act as a single compartment in equilibrium with vapor concentrations and, thus, had a very fast time constant. Although other models that do not incorporate a mucous membrane reservoir have successfully simulated inhalation exposure to methanol (e.g., Horton et al. 1992), these models were not utilized for short-term exposure, nor were sufficiently frequent blood measurements taken to observe the reservoir effect. Additional work is needed to confirm the reservoir effect, possibly using yet shorter periods of exposure and more frequent blood sampling.

It is clear that exposure and half-life estimates of water-soluble compounds should not be based on breath samples collected soon after a potential inhalation exposure. The equilibrium and multicompartmental models indicate that short-term processes, e.g., desorption, can dominate concentrations measured in breath. For methanol, at least $30 \mathrm{~min}$ is needed for breath samples to reflect alveolar air that is largely $(\sim 95 \%)$ free of solvent absorbed elsewhere in the respiratory system. This is longer than the 15 min we previously estimated (Franzblau et al. 1995) using 8-h exposure sessions. The short periods of exposure used in the present study provided better opportunities to evaluate breath monitoring as a BEI.

\section{Lung retention}

Sedivec et al. (1981) and other investigators calculate the lung retention by the difference in concentrations measured between inspired and expired air divided by the concentration detected in inspired air. Using averages, a $79 \%$ lung retention factor is calculated from the reported data as compared with the $58 \%$ value found by Sedivec et al. (1981) and the 65-74\% value found by our co-workers (Lee et al. 1992). Sedivec et al.'s results differ because we employed a breath-sampling maneuver designed to expel air from deep within the lungs, and the sampling apparatus excluded the first 0.51 of breath exhaled. Both steps were designed to exclude air from the tracheobronchial "dead space," where methanol 
concentrations may approach the chamber concentration, and to sample alveolar air, where concentrations should be much lower and reflect equilibrium with levels in blood.

\section{Clearance}

Methanol is excreted unchanged in urine and exhaled breath and is metabolized primarily in the liver. Because methanol's toxic acute properties are linked to intermediate metabolites, not the alcohol itself, the kinetics of the metabolic process are important (Kavet and Nauss 1990). Faster clearance of methanol would imply more rapid and severe formate generation and acidosis, as well as potentially greater acute toxicity. Several studies in humans have examined clearance (see the review of Kavet and Nauss 1990). Using oral exposure in three volunteers and urine sampling, Leaf and Zatman (1952) estimated that methanol disappearance followed first-order kinetics with a half-life of $\sim 3 \mathrm{~h}$. Using 8-h inhalation exposure, four volunteers, and urine sampling, Sedivec et al. (1981) estimated a half-life of 1.5$2 \mathrm{hr}$. Examining end-shift urine samples on occupational inhalation exposure and also earlier dermal exposure studies, Kawai et al. (1991) estimated a half-life of 7-8 h. The half-life estimates reported herein, i.e., $1.44 \pm 0.33 \mathrm{~h}$ in blood, $1.55 \pm 0.67 \mathrm{~h}$ in urine, and $1.40 \pm 0.38 \mathrm{~h}$ in breath (from the multicompartmental model) are consistent with those found by Sedivec et al. (1981). Leaf and Zatman's (1952) work may not be representative since oral exposure may involve a reservoir effect in the gastro-intestinal tract that increases the apparent half-life, and their results are based on only two subjects. Kawai et al.'s (1991) estimate is based on field conditions without controls on exposures, and it has the possibility of interferences. Laboratory studies should be free of these concerns. Dermal exposures also involve additional reservoirs and buffers that can bias half-life estimates (Batterman and Franzblau 1997). Note that the clearance of methanol can be much slower following high doses, i.e., the methanol half-life is $\sim 1$ day for doses exceeding $1 \mathrm{~g} / \mathrm{kg}$ (Kavet and Nauss 1990), and non-first-order kinetics (e.g., using the MichaelisMenton equation) may be needed to describe elimination (Droz and Fiserova-Bergerova 1992; Perkins et al. 1995). Such doses far exceed those used in the present study.

Half-life estimates based on blood, urine, and breath samples were comparable. Blood data had lower levels of uncertainty and may be somewhat more accurate since the time of collection can be accurately determined. In contrast, the urine samples represent time-weighted averages that require correction to the midinterval voiding time. Thus, postexposure or end-shift urine sampling seems unlikely to accurately reflect transient exposure. Breath samples are more difficult to interpret. Because desorption processes tend to cause very high initial concentrations, estimates of clearance or dose from breath samples must either use multicompartmental models or exclude data potentially affected, e.g., the first 30 min following an air exposure.

Evaluation of biological monitoring

for short-term exposures

The ability to quantify short-term inhalation exposure can be a rigorous test of a biological measurement, and the results of this study demonstrate several strengths and weaknesses of urine, blood, and breath measurements. In the 2-h 800-ppm exposure, which is equivalent to the concentration-time product of the TLV-TWA, the concentration of methanol in urine averaged $11 \mathrm{mg} / \mathrm{l}$, below the BEI $(15 \mathrm{mg} / \mathrm{l})$, and the peak lagged the termination of exposure by several hours. Soon after the exposure, blood concentrations averaged $14 \mathrm{mg} / 1$, close to the BEI. In practice, it is difficult to collect blood samples, especially after a short-duration exposure. Furthermore, the relationship between the exposure period and the concentration of biological samples is not expected to be linear unless clearance is slow relative to the exposure duration. If the partition coefficient is known, then doses can be derived from breath samples; however, breath sampling must occur at least $30 \mathrm{~min}$ after inhalation to allow sufficient desorption of solvent from the mucous membranes.

Measurements in breath, urine, and blood taken during and after short-term inhalation exposure can be used to estimate the dose received by an individual, given that the elapsed time since the exposure and firstorder corrections are made using appropriate methods. However, significant errors may result in quantification of the dose if exposures are transient and their timing is unknown. Nonetheless, because they incorporate the effects of physiological factors that affect the uptake and clearance of toxicants among individuals as well as the dermal exposure pathway, biological measurements offer advantages in comparison with area and environmental monitoring. The limitations of biological monitoring must also be viewed with respect to the feasibility and cost of monitoring of breathing-zone air.

In conclusion the experimental results showed consistent patterns with regard to the methanol concentrations detected in breath, urine, and blood following short-term inhalation exposure. As expected, concentrations did not increase linearly with exposure duration due to the fairly rapid clearance of methanol. Clearance half-lives estimated using blood, breath, and urine data were consistent, and the best estimate $(1.44 \pm 0.33 \mathrm{~h})$ is a meaningful change from the 3-h half-life often cited (e.g., Kavet and Nauss 1990). Lags in blood concentration with increasing exposure time provide support for a small reservoir or buffer for methanol, most likely in the mucous membranes of the respiratory tree. The same reservoir greatly increases breath concentrations for up to $30 \mathrm{~min}$ following exposure. Concentrations in 
blood and urine lag the exposure, and concentrations in urine do not reach levels expected, given the ACGIHrecommended BEI. Although the interpretation of biological samples for short-term exposure is more complex than that for exposure that is relatively constant over a shift, simple first-order models can be used to account for clearance during and following exposure.

Acknowledgements The authors thank Bryan Nakfoor, Hong-kui Xiao, Nathan Zhou, and Cathy Stephen for their assistance on this project and the reviewers for their helpful comments. This study was supported by grant 1 RO1 OH03024-1 from the National Institute for Occupational Safety and Health. Its contents are solely the responsibility of the authors and do not necessarily represent the official views of the National Institute for Occupational Safety and Health.

\section{References}

American Conference of Governmental and Industrial Hygienists (ACGIH) (1991) Methyl alcohol. Documentation of threshold limit values and biological exposure indices, 6th edn. ACGIH, Cincinnati, ohio.

Batterman S, Franzblau A, Zhou N (1996a) Contaminant fluxes from skin surfaces: a potential biological exposure indicator. Int J Occup Environ Health 68: 268-274

Batterman S, Xiao H, Franzblau A (1996b) Bioindicators for methanol exposure: effect of chilled and frozen sample storage. Appl Occup Environ Hyg 11: 25-29

Batterman S, Franzblan A (1997) Time resolved absorption and permeation rates of methanol in human volunteers. Int Arc Environ Occup Health 70: 341-351

Droz PO, Fiserova-Bergerova V (1992) Biological monitoring. VI. Pharmacokinetic models used in setting biological exposure indices. Appl Occup Environ Hyg 7: 574-580

Dutkiewicz B, Knocalik J, Karwacki W (1980) Skin absorption and per os administration of methanol in men. Int $\mathbf{J}$ Occup Environ Health 47: 81-88

Fiserova-Bergerova V, Diaz ML (1986) Determination and prediction of tissue-gas partition coefficients. Int Arch Occup Environ Health 58: 75-87

Franzblau A, Levine SP, Burgess LA, Qu QS, Schreck RM, D'Arcy JB (1992a) The use of transportable Fourier transform infrared (FTIR) spectrometer for the direct measurement of solvents in breath and ambient air. I. Methanol. Am Ind Hyg Assoc J 53: 221-227

Franzblau A, Levine SP, Schreck RM, D’Arcy JB, Qu Q (1992b) Use of urinary formic acid as a biologic exposure index of methanol exposure. Appl Occup Environ Hyg 7: 467-471

Franzblau A, Batterman S, D'Arcy JB, Sargent NE, Gross KB, Schreck RM (1995) Breath monitoring of inhalation and dermal methanol exposure. Appl Occup Environ Hyg 10: 833839

Franzblau A, Batterman S, Stephen C, Nakfoor B, D'Arcy JB, Sargent NE, Gross KB, Schreck RM (1997) Evaluation of methanol and formate in urine as biological exposure indices of methanol exposure. Appl Occup Environ Hyg 12: 367-374
Gerde P, Dahl AR (1991) A model for the uptake of inhaled vapors in the nose of the dog during cyclic breathing. Toxicol Appl Pharmacol 109: 276-288

Horton VL, Hiuchi MA, Rickert DE (1992) Physiologically based pharmacokinetic model for methanol in rats, monkeys, and humans. Toxicol Appl Pharmacol 117: 26-36

ICRP (1994) Human respiratory tract model for radiological protection. Report of Committee II of the International Commission on Radiological Protection. Cockermath, Cumbria UK

Johanson G (1991) Modelling of respiratory exchange of polar solvents. Ann Occup Hyg 35:323-339

Kavet R, Nauss KM (1990) The toxicity of inhaled methanol vapors. CRC Crit Rev Toxicol 21: 21-50

Kawai T, Yasugi T, Mizunuma K, Horiguchi S, Moriaoka I, Miuashita K, Uchida Y, Ikeda M (1991) Methanol in urine as a biological indicator of occupational exposure to methanol vapor. Int Arch Occup Environ Health 63: 311-318

Kawai T, Yasugi T, Mizunuma K, Horiguchi S, Moriaoka I, Miuashita K, Uchida Y, Ikeda M (1992) Monitoring of workers exposed to a mixture of toluene, styrene and methanol vapors by means of diffusive air sampling, blood sampling and urinalysis. Int Arch Occup Environ Health 63: 429-435

Kumagai S, Matsunaga I (1995) Physiologically based pharmacokinetic model for acetone. Occup Environ Med 52: 344-352

Leaf G, Zatman LJ (1952) A study of the conditions under which methanol may exert a toxic hazard in industry. Br J Ind Med 9: 19-31

Lee EW, Terzo TS, D'Arcy JB (1992) Lack of blood formate accumulation in humans following exposure to methanol vapor at the current permissible exposure limit of $200 \mathrm{ppm}$. Am Ind Hyg Assoc J 53: 99-104

Morris JB, Hassett DN, Blanchard KT (1993) A physiologically based pharmacokinetic model for nasal uptake and metabolism of nonreactive vapors. Toxicol Appl Pharmacol 123: 120-129

Murthy LI, Halperin WE (1995) Medical screening and biological monitoring, J Occup Environ Med 37: 170-184

Pezzagno G, Ghittori S, Imbriani M, Capodaglio E (1983) [Measurement of the coefficient of solubility of airborne substances in blood. II. Solvents of wide industrial use.] La misura dei coefficienti di solubilita degli aeriformi nel sangue. Nota IIa - I solventidi largo impiego industriale. G Ital Med Lav 5: 4963

Perkins RA, Ward KW, Pollack GM (1995) A pharmacokinetic model of inhaled methanol in humans and comparison to methanol disposition in mice and rats. Environ Health Perspect 103: 726-733

Rappaport SM, Spear RC (1988) Physiological damping of exposure variability during brief periods. Ann Occup Hyg 32: 21-33

Sedivec V, Mraz M, Flek J (1981) Biological monitoring of persons exposed to methanol vapours. Int Arch Occup Environ Health 48: 257-271

Wallace LA, Pellizzari ED (1995) Recent advances in measuring exhaled breath and estimating exposure and body burden for volatile organic compounds (VOCs). Environ Health Perspect 103 [Suppl 3]: 95-98

Yasugi T, Kawai T, Mizunuma K, Horiguchi S, Iwami O, Iguchi H, Ikeda M (1992) Formic acid excretion in comparison with methanol excretion in urine of workers occupationally exposed to methanol. Int Arch Occup Environ Health 64: 329-337 